\title{
Synthesis and Characterization of Vanadium-Strontium Apatite Type Structures
}

\author{
L. Bucio*, A. Tapia**
}

* Laboratorio de metalurgia, Instituto de Física, Universidad Nacional Autónoma de México, circuito exterior, Cd. Universitaria, 04510 México, D.F.

** Laboratorio de metalurgia, Instituto de Física, Universidad Nacional Autónoma de México, circuito exterior, Cd. Universitaria, 04510 México, D.F.

Scientists atention in compounds with apatite like structures had increased in the last years due to their applications as bioactive materials with high biocompatibility[1,2]. A lot of those compounds, with general formula $\mathrm{M}_{10}\left(\mathrm{XO}_{4}\right)_{6} \mathrm{Y}_{10}$, had been synthesized by a "chimie douce" method which consists of a precipitation reaction ocurring at a welldefined $\mathrm{pH}$ value[3]. In this work a vanadium-strontium apatite was sintetized and next treated thermically at temperatures in the range of $600^{\circ} \mathrm{C}$ and $800^{\circ} \mathrm{C}$. Polycrystals formation in the strontium hidroxiavanadate was confirmed and charaterized by Scanning Electron Microscopy (SEM), Transmition Electron Microscopy (TEM), Energy Dispersive Spectroscopy (EDS) and X-Ray difraction tecniques. The SEM microphotographs show multiple aglomerates while de X-Ray spectra shows corresponding apatite phase peaks

\section{References}

[1] Adriana Bigi et al., Inorganica Chimica Acta. 360 (2007) 1009-1016.

[2] Carlos Bauer Boechat et al., Phys. Chem. Chem. Phys. 2 (2000) 4225-4230

[3] S.Denis et al., J. Power Sources. 81-82 (1999) 79-84 


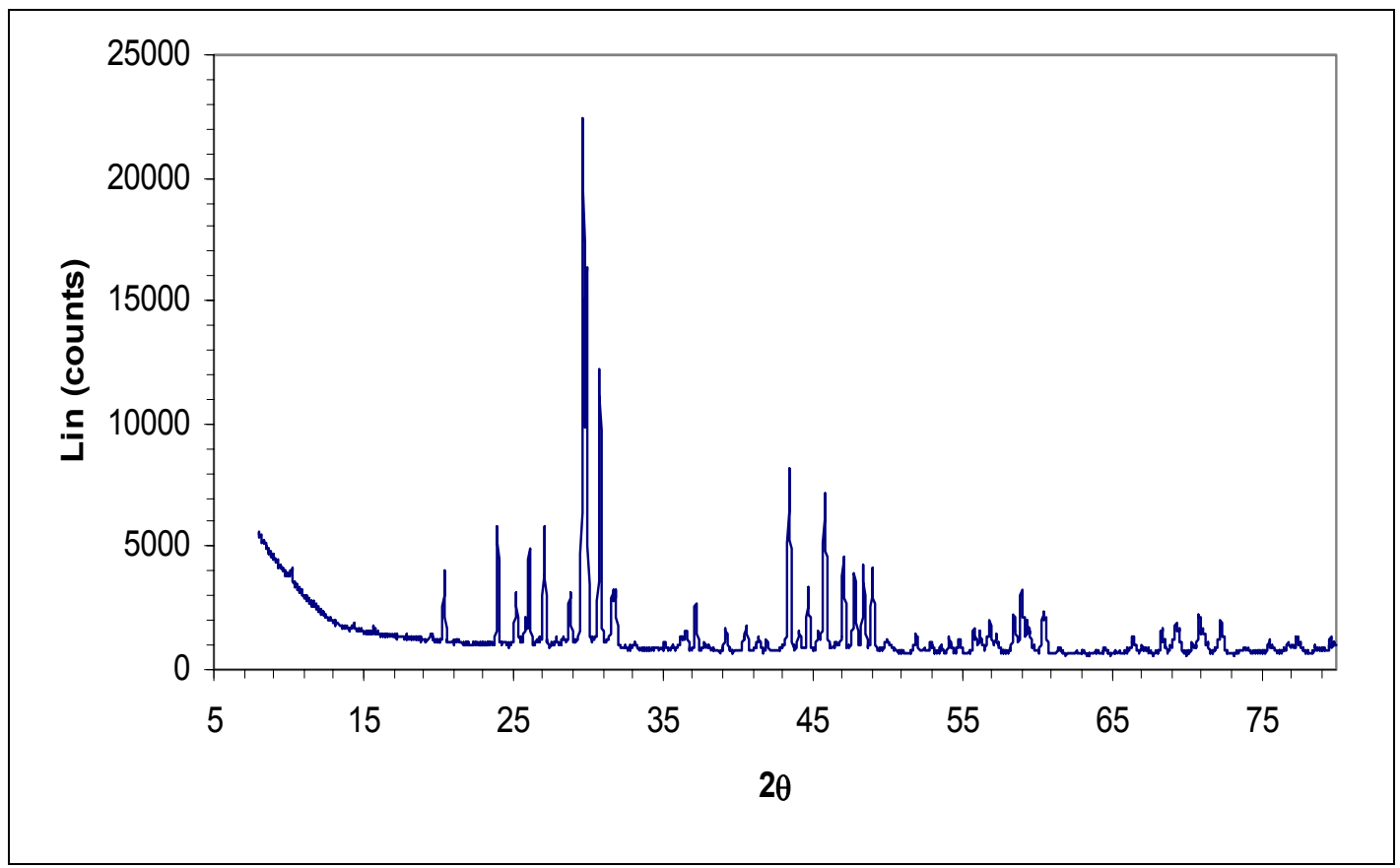

FIG 1 Energy dispersive X-Ray spectra of a strontium hidroxiavanadate showing corresponding apatite phase peacks.

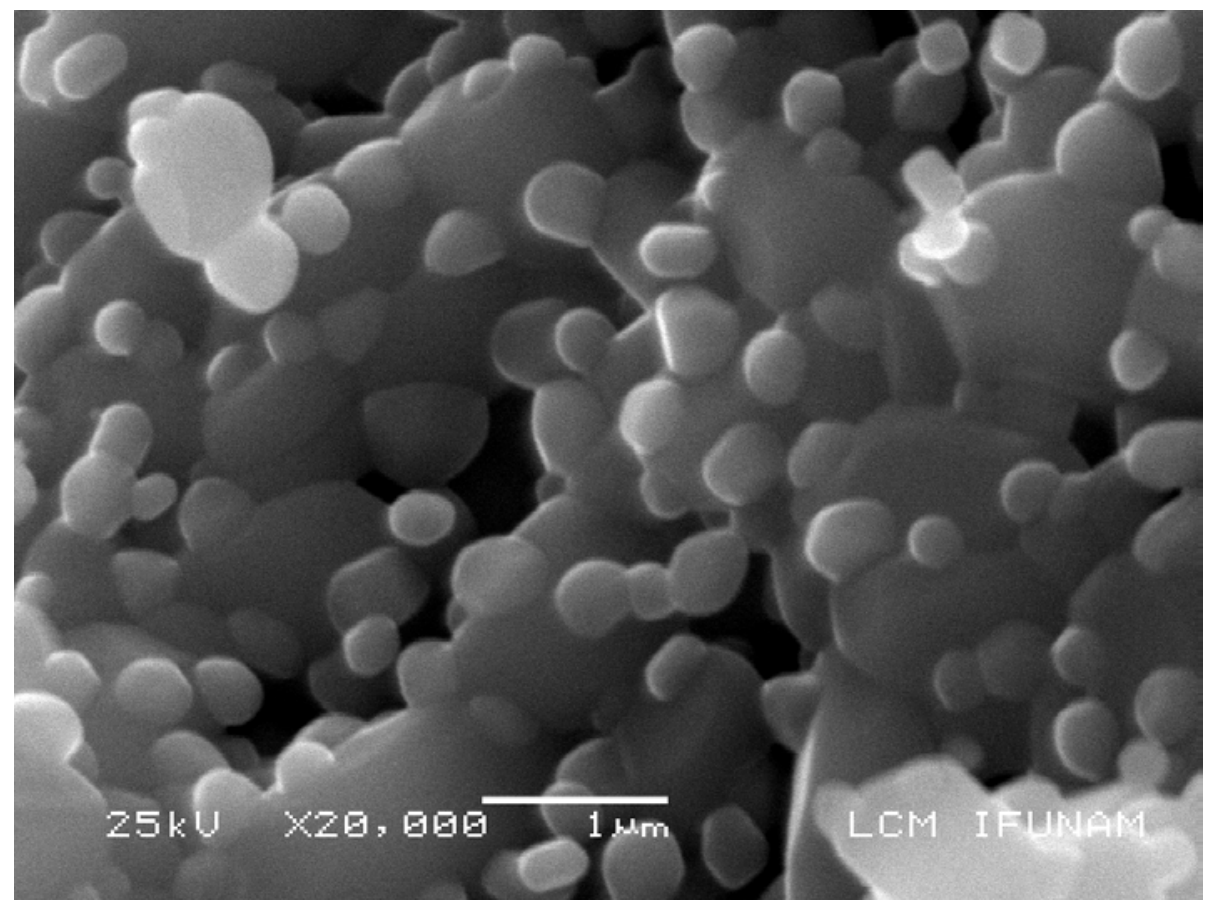

FIG 2 Scanning Electron Microscopy of a strontium hidroxiavanadate showing typical aglomerates 